\title{
Cuando la casa museo tiene su hortus conclusus. Una puesta en valor del patrimonio natural de las casas museo en España.
}

\author{
Soledad Pérez Mateo* \\ Ministerio de Cultura y Deporte (Epaña)
}

\begin{abstract}
Resumen: El jardín histórico de la casa museo es una unidad expositiva, como los restantes espacios domésticos "habitados" que se han musealizado. Este patrimonio natural, en sus aspectos tangibles, puede identificarse con una serie de elementos (sistemas de distribución del agua, elementos agropecuarios y construidos). Pero también es portador de unas expresiones de valor inmaterial que permiten que una persona o una comunidad puedan arraigar en ese lugar y generan un vínculo emocional con el visitante. Su apertura pública aumenta su fragilidad, por lo que su conservación debe guardar un equilibrio con su accesibilidad y no enfocarse desde la tradicional preservación de un monumento. Su carácter efímero requiere una formación específica en el campo de la conservación, cuyos planteamientos deben controlar las intervenciones para mantener su significación y no una alteración de sus valores. La dimensión cultural de este patrimonio debe servir de marco para la elaboración de estrategias de conservación.
\end{abstract}

Palavras Clave: Patrimonio natural; Jardín histórico; Casa museo; Huerta; Invernadero; Patrimonio inmaterial.

When the house museum has its own Hortus Conclusus. Enhancing the natural heritage in the house- museums in Spain.

Abstract: A historical garden in a house-museum is as much a part of the exhibition as the interior museum living space. This natural heritage, in its tangible aspects, is identified to a series of elements such as water supplies, and other rural or urban elements. Gardens offer spaces for a person or community to enjoy and therefore, offer potential intangible heritage with which the visitor may emotionally connect. The opening to public visits, however, may increase the fragility of these resources. Therefore, an appropriate balance should be struck between accessibility and preservation. The ephemeral nature of this element within the house-museum complex requires specific conservation strategies that do not apply elsewhere in order to maintain their historical value. The cultural dimension of this heritage should be the priority in the elaboration of conservation strategies.

Keywords: Natural heritage; Historical garden; House museum; Orchard; Greenhouse; Intangible heritage.

\section{Introducción}

En este estudio reflexionamos sobre el patrimonio natural de la casa museo, que a menudo pasa desapercibido, analizando su concepto, como portador de unos elementos materiales e inmateriales que lo hacen susceptible de formar parte del acervo cultural de nuestro patrimonio, y su significado como elemento propio de la casa museo. El componente cultural de este patrimonio fue subrayado por la Convención del Patrimonio Mundial, adoptada por la Conferencia general de la UNESCO en 1972', al reconocer la interacción del hombre en la naturaleza y la necesidad de proteger el equilibrio entre ambos. Es una unidad expositiva de la casa museo, formando con ella una unidad cultural que, en ocasiones, le supera en concepción escenográfica, en antigüedad e incluso, en belleza, siendo la casa

Ministerio de Cultura y Deporte (Epaña); E-mail: soledad.perez.m@cultura.gob.es 
subsidiaria de la importancia del jardín (Martínez-Correcher Gil, 2000: 13). Por ello, debe ser objeto de investigación en los estudios museológicos y patrimoniales, puesto que éstos se centran más en el jardín vinculado a edificios representativos de la cultura española. Nos referimos, por ejemplo, a los jardines históricos del Alcázar de Sevilla², de los palacios, conventos y monasterios de Patrimonio $\mathrm{Nacional}^{3}$; de la Alhambra o del Generalife, los de Gaudí, entre otros. El jardín histórico de una casa museo, término que empleamos como sinónimo de patrimonio natural, es un bien integrante del patrimonio histórico español, por lo que debe estar correctamente documentado. Esto implica una identificación de los diferentes elementos que lo componen y de sus valores inmateriales. Defendemos una visión inclusiva que integre valores más amplios que son compartidos por sociedades cada vez más plurales. En este sentido se deben promover iniciativas de conservación que se encaminen hacia escenarios de sostenibilidad y formar parte de una política proteccionista que explique sus beneficios para la educación, el ocio o la cultura de los ciudadanos. La ausencia o insuficiencia de esfuerzos en su conservación no se debe justificar por desinterés, por la carencia de recursos humanos o económicos, ni tampoco por la idea de que no es posible recuperarlo o reconstruirlo como estaba originalmente. Partiendo de un correcto diagnóstico previo, y sin caer en falsas interpretaciones, puede tener sentido su protección. Este patrimonio natural es muy diferente entre sí, en sus características ambientales y socioeconómicas, desde pequeños hábitats hasta grandes extensiones. Es necesario que existan planes de gestión que definan los objetivos específicos para la conservación de estos espacios y las actuaciones concretas para alcanzarlos. Asimismo, analizamos sus implicaciones de uso público, porque es un bien susceptible de atraer y hacer disfrutar a los visitantes. Esta apertura pública aumenta su fragilidad, por lo que su conservación debe implicar un equilibrio con un desarrollo sostenible. Los proyectos de la Casa de las Doñas (Enterrías, Cantabria) y el Caserío Igartubeiti (Ezkio-Itsaso, Guipúzcoa), que desarrollamos más adelante, son paradigmáticos al ser experiencias etnográficas que se promocionan como agricultura ecológica o que participan en programas de desarrollo rural.

La historiografía del jardín español se ha centrado más en trazar el concepto e historia del mismo; las tendencias formales; la topografía donde se asienta; los cursos de agua; la historia de los palacios reales, de la nobleza o de la burguesía en los que se ubica, o en situarla en el eje de las reivindicaciones urbanas e higienistas, que en analizar las transformaciones que experimenta cuando el inmueble se transforma en casa museo, especialmente las relativas a su autenticidad; a la afluencia y recepción de visitantes; a las estrategias de información, comunicación y sensibilización social, o a la capacitación del personal encargado de su conservación. En España son pocos los especialistas formados en el estudio de los jardines históricos. Los trabajos académicos suelen presentar una doble vertiente, física y cultural. En el primer caso, se relacionan con la ordenación territorial, el urbanismo, la botánica, la agricultura o la arquitectura, mientras que en el segundo caso son la historia, la literatura, la escultura o la pintura, que inciden en su aspecto sensorial, en los factores culturales, en informaciones planimétricas, en tratados arquitectónicos, botánicos o específicos de jardines, en las diferentes etapas de su proceso constructivo, en las influencias extranjeras, o en sus autores. Es necesaria una perspectiva holística que integre el trabajo de historiadores, arquitectos, ingenieros, paisajistas, entre otros.

Generalmente la atención se centra en los espacios naturales públicos (parques, jardines botánicos y otras zonas verdes urbanas) y en los de inmuebles de propiedad privada o que no están reconocidos institucionalmente como "casas museo" ${ }^{4}$ que en los de las propias casas museo. Ejemplos de esta situación se encuentran en las actividades llevadas a cabo por grupos de investigación de diferentes universidades españolas sobre el paisaje y de asociaciones centradas en la difusión y gestión de este patrimonio natural, como la Asociación Española de Parques y Jardines Públicos ${ }^{5}$, que promueve cursos de formación específicos y tiene su propia revista, PARJAP. La Fundación de Casas Históricas y Singulares (FCHS) ${ }^{6}$ fue pionera en el interés mostrado hacua los jardines históricos privados de España con la organización de dos jornadas, una en 1999, Jardines históricos privados. Espacios por descubrir (FCHS, 2000) y otra en 2000, Jardines históricos privados. espacios sobresalientes a conservar (FCHS, 2002). La desaparición de numerosas viviendas por la especulación, el abandono o el paso del tiempo, también ha afectado a sus jardines, urbanos y rurales, desvirtuando incluso el entorno donde estaban. Por ello, los propietarios de inmuebles que aún subsisten deben considerarse un archivo vivo, porque son los depositarios de un conocimiento derivado de su pertenencia (Martínez-Correcher Gil, 2000: 15-16). Además, está comprobado el éxito de las visitas a estos jardines privados, con una enorme afluencia de público. Su apertura restringida en determinadas circunstancias, con visitas programadas, es una medida que está ayudando a que estos jardines sean sostenibles y rentables (Martínez-Correcher Gil, 2000: 25). Asistimos a un cambio de paradigma en la toma de conciencia ambiental y, en este sentido, 
subrayamos la necesidad de una actitud más respetuosa con el patrimonio natural, incluyendo el de las casas históricas y casas museo.

Este patrimonio natural ya fue objeto de interés en el primer tercio del siglo XX, por ejemplo, los norteamericanos Arthur Byne y Mildred Stapley ${ }^{7}$ señalaban la escasa atención prestada a los "viejos jardines":

"Outside of Catalonia no group of investigators has appointed a competent photographer to record the artistic wealth of its region and to put such photographs within reach of students. If great architectural monuments have not received this merited attention, how much less have old gardens. The only exception to this general observation would be perfectly obvious views sold to tourists in Seville and Granada" (Spanish Gardens and patios, edición de 1928: 11)

Entonces el jardín español se identificaba con el árabe, hecho que implica que los que respondían a las tendencias europeas no se consideraban propiamente españoles (1928: 10). Lo que explica el mayor protagonismo de los jardines andaluces y mallorquines. En 1928 Byne y Stapley publicaron un libro con el significativo título de Majorcan Houses and Gardens, que influirá en los regionalismos y en los nuevos estilos norteamericanos (Mulet et al, 2019: 2000).

\section{2. ¿Qué entendemos por patrimonio natural de una casa museo? Definición de jardín histórico}

Consideramos la casa museo como algo más que una morada con unos espacios domésticos habitados que se han musealizado, porque sus formas de vida se extienden al exterior, en un patrimonio natural al que nos referimos con el término de "jardín", que puede o no incluir elementos agropecuarios (huerta, invernadero, vivero) y que consideramos "histórico", categoría cultural contemplada en la Ley 16/1985, de 25 de junio, del Patrimonio Histórico Español (LPHE). La misma comprende jardines de casas, palacios, villas, parques, jardines botánicos, espacios verdes de centros urbanos, entre otros y que recoge la LPHE como "el espacio delimitado, producto de la ordenación por el hombre de elementos naturales, a veces complementado con estructuras de fábrica, y estimado de interés en función de su origen o pasado histórico o de sus valores estéticos, sensoriales o botánicos" (art. 15.2). La morada se prolonga al exterior mediante los diferentes espacios del jardín, hasta el punto de que "el jardín ordenado es a la casa lo que el zócalo a la estatua: el basamento donde se coloca" (Muthesius, 1979: 107). Reivindicamos que los jardines históricos de las casas museo son dignos de figurar en cualquier antología del jardín, puesto que constituyen, además de su indudable calidad o interés botánico, un testimonio sociológico de búsqueda de un espacio diferenciado y privilegiado, donde el propietario proyecta sus deseos y aspiraciones, y ligado al lujo, a lo lúdico y escenográfico, a la sociabilidad o al prestigio. Los consideramos una suerte de designed landscape $e^{8}$, un paisaje cultural en tanto que son definidos, diseñados y creados intencionadamente por el hombre, con frecuencia relacionados con edificios. Si pensamos en términos de monumentalidad, no se pueden comparar los jardines del Palacio de La Granja (Madrid) con los de la Casa Museo Rosalía de Castro (Padrón, La Coruña). Pero ambos son elementos clave en la definición de una identidad territorial por los siguientes aspectos:

- Representan la singularidad de un lugar en tanto que son un atributo que permite comprender un pasado.

- Tienen un interés patrimonial, en sus aspectos históricos y botánicos, porque, como documentos, nos remiten a un pasado (político, económico, agrícola, botánico, rural, urbano).

- Su dinámica depende de su ciclo natural y de la alteración de su uso y funciones.

- Son objeto de percepciones y vivencias subjetivas, puesto que, tanto sus propietarios como el público, han proyectado sus emociones en ellos.

Este jardín histórico es una unidad expositiva ${ }^{9}$ de la casa museo, de la misma manera que los espacios domésticos del interior (dormitorio, comedor, cocina, etc.). Como espacio musealizado revela la vida cotidiana de una personalidad y refleja el grado de cultura del propietario, que lo construye a su escala, para uso exclusivo o el de su selecto círculo. Por ello, es más frecuente encontrarlo en las casas museo de personalidad ${ }^{10}$, puesto que su creación se vincula a una familia de fortuna, a un personaje poderoso o a un artista asentado en la localidad. Por ejemplo, las Casas del Volcán (Taro de Tahíche, Lanzarote), antigua residencia de César Manrique y actual sede de la fundación que lleva su nombre, 
y del Palmeral (Haría, Lanzarote), en la que vivió hasta su muerte, son construcciones cuyos elementos naturales aprovechan las características inherentes al lugar. Su lenguaje propio, que resalta la belleza de la naturaleza, supone un compromiso y una defensa del patrimonio natural insular (Díaz, 2009: 131).

Es inseparable de la tipología de la morada en un territorio (pazo gallego, carmen granadino, son mallorquín, cigarral toledano, caserío vasco, etc.). Un ejemplo es el Carmen granadino, vivienda de origen musulmán inseparable de su jardín de huerta, dispuesto en terrenos aterrazados. Algunas se han conservado como casas museo: la casa-estudio y el jardín del pintor José María Rodríguez-Acosta en la colina del Mauror, hoy sede de la Fundación Rodríguez Acosta (Granada). Estos jardines históricos oscilan entre los de pequeño tamaño hasta extensiones considerables de terreno. Suelen constar de todos o alguno de los siguientes elementos: el edificio principal (castillo, cortijo, palacio, etc.); las construcciones a dosadas o exentas a la vivienda (invernaderos); el jardín ornamental (con una función de deleite); el jardín-huerta (de carácter productivo); el parque; el bosque; el campo o el patio, que debe ser reconocido como jardín tipológico (Martínez-Correcher Gil, 2000: 27). Como espacio de uso doméstico que satisface las necesidades de individuos, responde a unas preferencias estéticas, por ejemplo, los hay de inspiración medieval islámica, renacentista (modelo italiano), barroca (modelo francés), neoclásica (modelos franceses e italianos), romántica (modelo inglés), historicista, ecléctico o producto del gusto propio de su creador (Pasti, 2014). Esta variedad de estilos puede coexistir, por ejemplo la vemos en los jardines del palacete asturiano de La Quinta (Cudillero, Asturias) ${ }^{11}$, divididos en tres zonas: el Parterre sur, de inspiración francesa, con su geometría rigurosa; el Parterre norte, de impronta italiana, es un jardín regular con un gran estanque central, delimitado por el palacete, los pabellones de Tapices y de Invitados, así como el invernadero; y al Este alcanza su máxima extensión, adoptando las formas de la naturaleza dejándose sentir la impronta inglesa ${ }^{12}$, reforzada con la presencia del templete jónico sobre una gruta o el pabellón chinesco. Morales Saro señala que el palacete es una tipología escasa en España, porque se ubica en una zona rural y no se vincula a una explotación agraria, cuando no existe una tradición de jardines privados en el campo, sino en zonas urbanas (1994: 264). Se destinaba exclusivamente para su disfrute durante los meses de verano.

Revistas como La Ilustración Española y Americana o Los Salones de Madrid ilustraron los encuentros sociales y fiestas celebradas en los invernaderos, así como las exposiciones de plantas en Madrid (Spala, 2014). Estos invernaderos, también denominados estufa o serre, aparecen tanto en el interior del inmueble (Museo Cerralbo, Madrid), como al exterior (Fundación Selgas-Fagalde, Cudillero). Forman parte de ese patrimonio natural, porque servían para mostrar y conservar las colecciones de especies exóticas ${ }^{13}$ y para la aclimatación y experimentación científica. Sin embargo, otros servían de transición entre la vivienda y el jardín, cerraban balconadas o se colocaban en azoteas, como el del Museo Nacional del Romanticismo (Madrid), recreado aprovechando una galería de paso. Son conocidos los de los Reales Sitios y palacios (Palacio del Marqués de Salamanca, Palacio de Fernán Núñez, Palacio de Montijo, Hotel de los Olabarri, entre otros) ${ }^{14}$. El Marqués de Cerralbo concibió en su palacio, hoy Museo Cerralbo, un invernadero, pero debió ver este espacio poco práctico dado el clima de Madrid y lo convirtió en un gabinete de coleccionista ${ }^{15}$. Es el denominado "Salón Estufa" en el Inventario de $1924^{16}$ del primer director del museo, Juan Cabré, y que en el año 2013 se ha recuperado como se encontraba en el momento de la muerte del marqués. Esta pieza gozó de predicamento en la arquitectura doméstica inglesa, llegando a alcanzar grandes dimensiones, como la construida por Thomas Chambers Hine en Flintham Hall (Nottinghamshire, 1851-7).

\section{El patrimonio natural de una casa museo. Su dimensión material e inmaterial}

\subsection{Dimensión material}

Es necesario que existan iniciativas de las administraciones públicas y/o privadas, materializadas en disposiciones legales y administrativas que permitan identificar, inventariar y proteger los jardines vinculados a casas museo; en el desarrollo de planes de seguimiento (censos periódicos de especies botánicas y animales, registro de variables meteorológicas o de calidad del aire, etc.), así como disposiciones económicas que favorezcan su mantenimiento, conservación y restauración. Un estudio de su localización y número permitiría crear un archivo documental, con el que podremos conocer cuáles son los aspectos arquitectónicos, históricos y paisajísticos más destacados, y la superficie que ocupan para delimitar su ámbito de aplicación. Su catalogación es una garantía para evitar modificaciones arbitrarias y amenazas externas (presión del suelo, obras públicas, etc.). Podríamos diferenciar entre los siguientes elementos:

Los sistemas de distribución del agua ${ }^{17}$ (aljibes, albercas, surtidores, canales). Suelen responder a la idea de jardín de placer, pero también pueden tener una función práctica (aprovechamiento del suelo para el cultivo y suministro de agua para las fuentes y riego), además de estética (colocación de fuentes y elementos escultóricos como capiteles, esculturas, materiales cerámicos). El agua determina 
la configuración del jardín del Museo Sorolla (Madrid), de influencia hispanoárabe por la presencia de las albercas, que se racionalizan con las acequias, la elevación de los paseos o los rincones destinados al reposo. Su pequeño tamaño favorece el uso racional del agua y crea más zonas de sombra, aumentando la humedad relativa y, por tanto, el confort térmico. Está compartimentado en tres zonas, diferenciadas por escalones y columnas. El pintor Joaquín Sorolla los diseñó a partir de 1910, con la construcción de su casa ${ }^{18}$, inspirado en los que conoció durante sus viajes a Andalucía, en concreto del Alcázar sevillano o los de la Alhambra y del Generalife de Granada, que también reflejó en sus lienzos.

Los elementos agropecuarios (huertas, invernaderos o viveros, donde se implantan cultivos propios o importados). Responden a la idea de un jardín de producción, destinado a obtener productos primarios animales o vegetales (agricultura, horticultura, agricultura o cría de ganado, entre otros), así como su repoblación. Nos informan de un contexto geográfico y socioeconómico, de las características morfoclimáticas, de la diversidad de su agricultura, de la capacidad productiva de la tierra, del desarrollo ganadero, de la superficie cultivada y la disponibilidad de la tierra, entre otros. El jardín-huerta de la casa museo sirve tanto para el deleite como para el autoabastecimiento. De tradición arraigada en España, en él se cultivaban plantas aromáticas, árboles frutales y productos hortícolas. Es un paisaje cerrado y delimitado por muros de piedra o árboles frutales. También puede tener zonas de arbolado de producción (almendros, olivos, viñedos) y otros cultivos no relacionados con la alimentación, pero que generaban materias primas para actividades industriales, como por ejemplo el cáñamo que se cultivaba en los huertos de Aranjuez (Añón Luengo, 2008:87). Suele presentar una pluralidad de cultivos, de uso temporal y cambiante, en paralelo al devenir de las estaciones del año y del medio local. Recordemos, por ejemplo, los jardines de huerta de la Casa Museo Lope de Vega (Madrid) (Fig. 1); de la Casa Museo Miguel Hernández (Orihuela, Alicante) o de la Casa Robert Graves (Deià, Mallorca).

Figura 1: El huerto y el jardín de la Casa Museo Lope de Vega (Madrid)

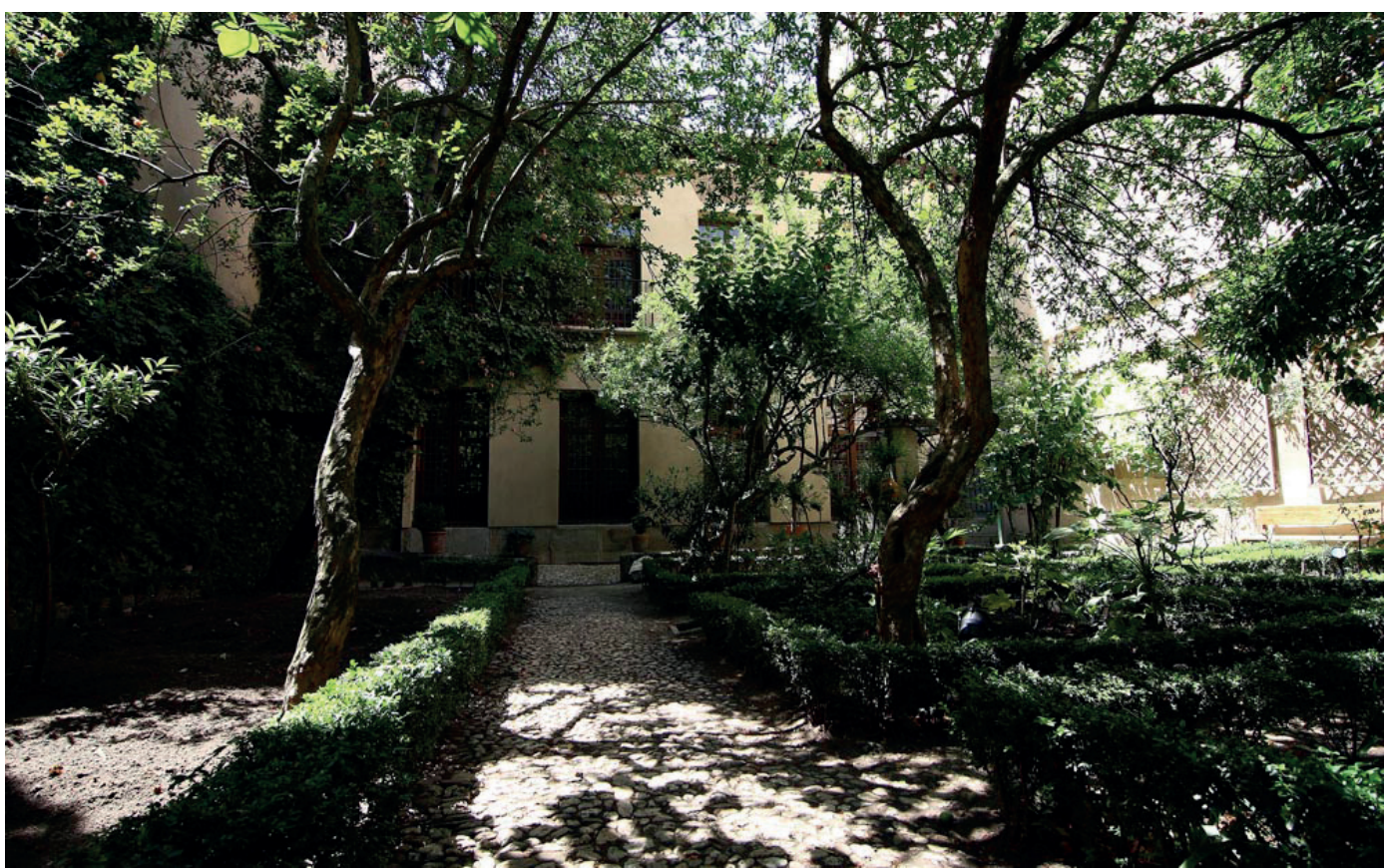

(C) Comunidad de Madrid 2015-2017

Los elementos ordenados o construidos (parterres, céspedes, emparrados, enredaderas o macetas). Se vinculan a un jardín de placer, y determinan la idea de apertura o cerramiento. El hecho de estar acompañados de elementos arquitectónicos (terrazas, fuentes, estanques, grutas, invernaderos, pabellones, pérgolas, etc.) subraya la belleza natural del lugar. Destacamos, por ejemplo, el patio, que es un jardín 
intramuros, como la serre, y presentaba flores aromáticas y ornamentales, plantas trepadoras o árboles variados. Los hay en la Casa Museo Bonsor. Castillo de Mairena (Mairena del Alcor, Sevilla), en el Museo Casa de Cervantes (Valladolid) o en el Palacio de Viana (Córdoba). Pero, por su rareza, no podemos dejar de mencionar el laberinto de piedra del Museo Pazo de Tor (Monforte de Lemos, Lugo), fechado en el siglo XVIII y compartimentado en cuatro espirales cada una, con un estanque en el centro (Fig. 2).

Figura 2: Laberinto del Museo Pazo de Tor

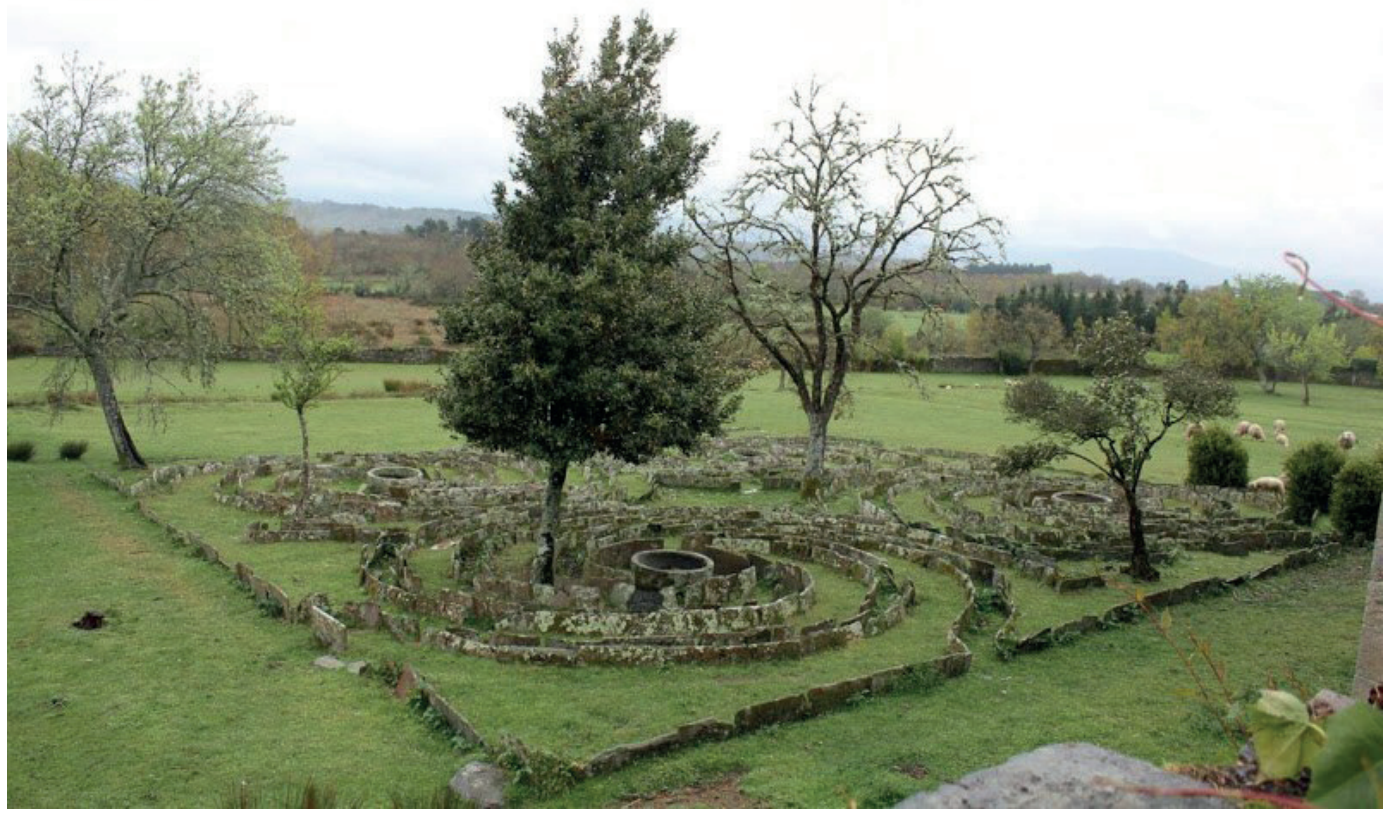

(C) 2018 Galicia Máxica

\subsection{Dimensión inmaterial}

El reconocimiento del aspecto inmaterial del paisaje es habitual en el mundo anglosajón, ligado, entre otros aspectos, a la tradición Arts \& $\mathrm{Crafts}^{19}$, y en Estados Unidos ya en el siglo XIX se tuvo en cuenta la iniciativa de la Mount Vernon Ladies 'Association (MVLA), para conseguir la protección del jardín y la huerta de la casa de George Wasinghton (1856). En España sigue siendo un tema incipiente, sobre todo aplicado al jardín de una casa museo, que tiene una idiosincrasia intrasferible, porque es un espacio cargado de numerosas referencias personales. El componente inmaterial debe incorporarse a los planes museológicos, para permitir su conservación y difusión, y contemplar un enfoque participativo que integre múltiples grupos de interés, como las iniciativas de investigación y difusión del Parque Natural y Reserva de la Biosfera del Montseny, que han dado lugar, entre otros equipamientos culturales a la creación de la Casa Museo de Agustín (Tagamanent, Barcelona). En esta línea destaca el Programa de trabajo para las áreas protegidas ${ }^{20}$ del Estado español 2009-2013 impulsado por EUROPARC-España, que incluyó un apartado dedicado a los valores culturales y espirituales del patrimonio natural. Una visión más integradora o inclusiva debe reconocer los diferentes modos de conocimiento y expresión que existen en ese patrimonio natural.

Estos jardines históricos no son necesariamente monumentales, ni predominantemente los más relevantes, sino que también tienen el encanto de lo cotidiano, lo que ha condicionado que a menudo hayan pasado desapercibidos. Su riqueza inmaterial reside en que son espacios vividos y, por lo tanto, hay que valorarlos socialmente. Nos retrotraen a las dinámicas culturales que lo han construido y que lo dotan de significado (elementos asociados a fiestas, ceremonias, rituales, relatos e incluso acontecimientos históricos). Hay árboles comunes (palmeras, pinos, olivos) que para su propietario tienen un 
valor sentimental, les acompañan en sus recuerdos y deleitan a los visitantes. Por ejemplo, el olivo del jardín de la Casa José Saramago (Tías, Lanzarote), un árbol vinculado a su infancia; el olmo, plantado por el propio Saramago, en homenaje a su sobrino Olmo; o las membrilleras, en recuerdo del pintor Antonio López y el director de cine Víctor Erice (Fig. 3).

\section{Figura 3: Silla de José Saramago en el jardín de A Casa en Lanzarote}

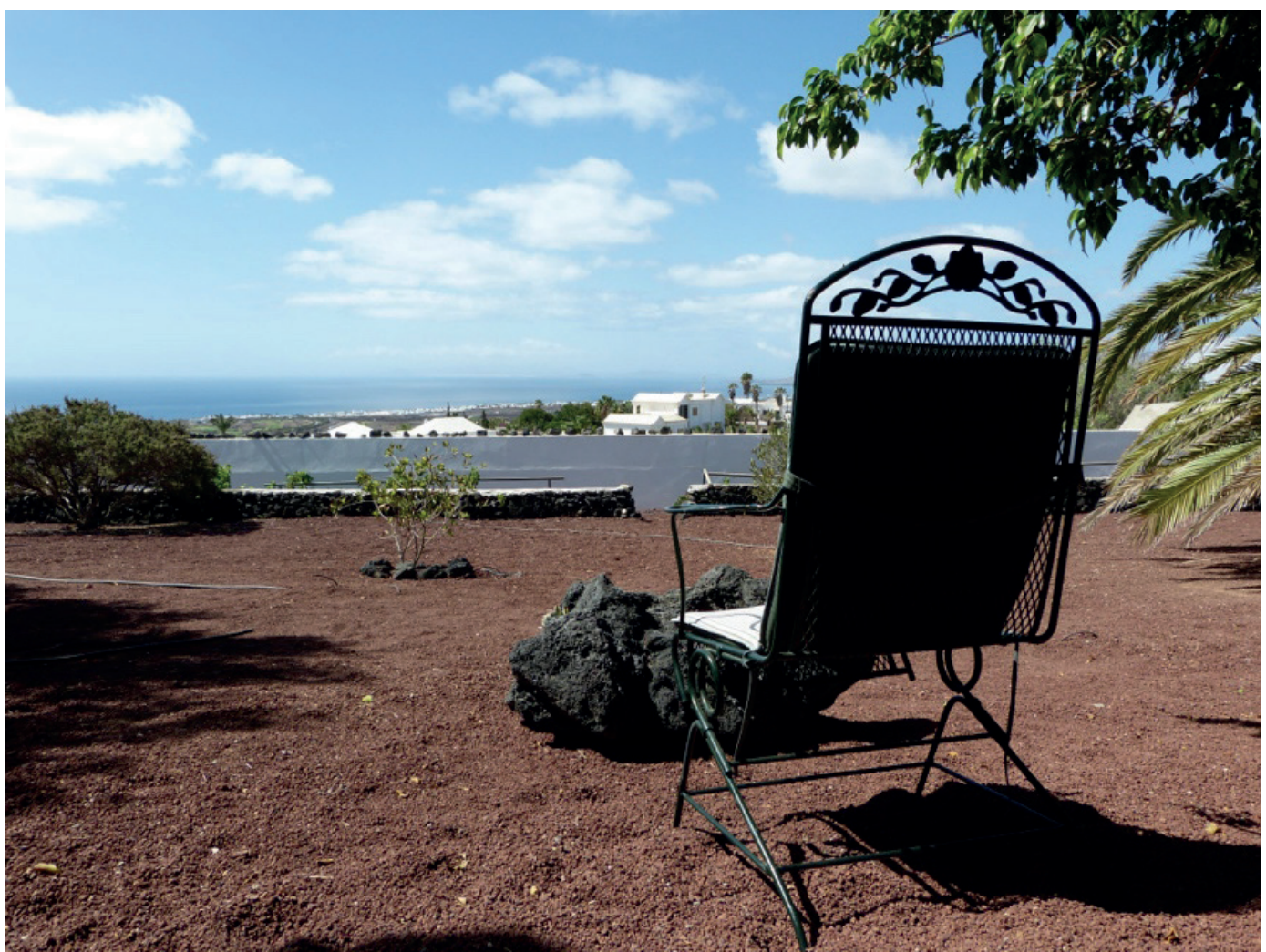

(C) A Casa Museo José Saramago

Estos valores son una riqueza añadida a la casa museo, porque permiten que una persona o una comunidad puedan arraigar en ese lugar y generan un vínculo emocional con el público. Lo que remite al concepto de espacios afectivos o geografías emocionales, término que ha tenido un largo recorrido en la historia de la Geografía, por ejemplo, ha sido abordado tradicionalmente en el mundo anglosajón, como las Emotional Geographies de Bondi, Smith y Davidson (2005). El espacio no es una mera localización física, sino que está impregnado de emociones que permiten explicar cómo el ser humano interactúa con el entorno. Así, las emociones se entienden más como una construcción social que como un atributo individual, puesto que se basa en aspectos sensoriales, afectivos y cognitivos. Es lo que Nogué denomina "el retorno de las emociones a la esfera pública" (2015:140). Los jardines históricos, al igual que los restantes espacios domésticos de la casa museo, serían espacios creados por sus propietarios, vividos y dotados de significado, que pueden explicar por qué y cómo se relacionan con ellos. De la misma manera que a su propietario el jardín le producía sensaciones de paz, de tranquilidad, de deleite, para el público hoy es sugestiva la combinación de la arquitectura y la vegetación, el colorido, la variedad y la envergadura de las especies vegetales, la sensualidad de sus olores, los sonidos de los animales, la presencia del agua y los reflejos que produce ${ }^{21}$. Tanto el dueño de la vivienda, que proyecta sus emociones en su jardín, como el público, en quien el jardín despierta la capacidad de conmoverse, se sienten identificados con un espacio determinado, teniendo en cuenta los factores culturales, sociales 
o personales. Ese poder de la identidad no desaparece en la era de la información en la que estamos inmersos, sino que se refuerza (Castells, 2013).

\section{Una puesta en valor del jardín histórico. Su uso público}

El jardín histórico, como espacio existencial, formó parte de la vida cotidiana de sus moradores (reyes, nobles, burgueses, terratenientes, artistas) y era uno más de los elementos que constituían su vivienda. Y ahora, convertido en un espacio público vinculado a la casa museo, se muestra al visitante como un lugar tan simbólico y social como material. Su atractivo es indudable y puede provocar en el visitante sensaciones muy agradables o que merezcan la pena repetirse. Por ello, deben crearse experiencias más participativas, en la línea de la ampliación de los fines del museo que se vienen incluyendo en las definiciones canónicas del muse ${ }^{22}$. El conocimiento y el aprendizaje significativo implican una transmisión de información y de experiencias positivas, elementos que permiten una experiencia museística de calidad. En este sentido, la educación es una herramienta fundamental en la generación tanto de conocimientos como de actitudes positivas hacia el paisaje y sus valores materiales e inmateriales (Busquets, 2010), lo que será una garantía de su valoración y conservación a medio y largo plazo.

La apertura pública convierte a los jardines de las casas museo en bienes sensibles y con riesgos inherentes como las visitas masivas, el uso puntual en eventos (festivales de música, iluminación nocturna y otras actividades culturales) y la alteración de sus valores, puesto que su función puede haberse modificado a lo largo de su historia. Si compleja es la visita por la dificultad de ajustarse a los requerimientos funcionales que garanticen una utilización autónoma y con comodidad a cualquier persona, lo es más para el visitante con discapacidad por presentar generalmente espacios abiertos o zonas estrechas sin pautas de referencia, desniveles, escalones o elementos salientes, entre otros aspectos. En los últimos años estamos asistiendo a actuaciones de accesibilidad, por ejemplo, la pavimentación del acceso al jardín de la Casa de Robert Graves (Deià, Mallorca), en el que el escritor plantó naranjos, mandarinas y limoneros, así como variedades locales de árboles frutales para fabricar su mermelada. No deben ser proyectos aislados, sino formar parte de un programa de accesibilidad que esté pensado para todas las personas, con independencia de sus características, en la línea de los principios del diseño para todos. El término accesibilidad, que tiene un carácter transversal en las cuestiones planteadas en la Carta Europea de Turismo Sostenible, es determinante en el incremento de la calidad de la visita y en el atractivo que puede generar en el público.

Constituyen una excepción aquellos jardines que, desde el mismo momento de su creación, tuvieron un uso público. Como los de la Finca del Marqués de Valdecilla (Medio Cudeyo, Asturias), que en vida de su propietario, Ramón Pelayo de la Torriente (Valdecilla, 1850-1932), disfrutaban los habitantes de Medio Cudeyo porque dentro de la actual finca se encontraba la bolera municipal. Cuando su sobrina y heredera $\mathrm{M}^{\mathrm{a}}$ Luisa, marquesa de Pelayo, se fue a vivir a la finca trasladó la portalada del siglo XVII que da acceso al recinto y se cerró con unos muros que lo alejaron un uso público, que el Ayuntamiento de Medio Cudeyo ha recuperado en la actualidad para el visitante (Fig. 4)

En la actualidad no existe una dicotomía entre la conservación de la naturaleza y la del patrimonio cultural. La Carta de Florencia (1981) señala que el jardín histórico no debe desligarse de su entorno (art. 7) y ser conservado en un entorno apropiado (art. 14), que debe comprender la unidad arquitectónica con el jardín y las infraestructuras externas al mismo (red viaria, plazas, calles, canales, instalaciones de riego, drenajes, saneamiento, entre otros). Asimismo, el art. 9 contiene dos aspectos de interés: la exigencia de que estén identificados e inventariados, y el establecimiento de diferentes tipos de intervención (mantenimiento, conservación y restauración, siendo recomendable en algunos casos la recuperación) ${ }^{23}$. En España son escasos los acercamientos al tema de la restauración de jardines. Sin pretender ser exhaustivos, destacamos, por ejemplo las publicaciones de Carmen Añón (1991, 1992 o 1993), Casares Porcel y Tito Rojo (1998, 1999a, 1999b), Tejedor Cabrera (1998, 1999), o Martínez-Correcher y Gil (2011), entre otros. Aunque el jardín histórico está reconocido como un bien cultural, no se le pueden aplicar los mismos parámetros de conservación-restauración que a los bienes muebles o inmuebles por las siguientes razones:

- Es un ser vivo, lo que implica un continuo cambio y una vida perecedera debido a su propia naturaleza.

- Su carácter polimatérico (Tito Rojo y Casares Porcel, 1999b:141). Hay elementos naturales y arquitectónicos, así como otros ajenos a los límites del jardín.

- Los cambios tanto sociales, culturales o artísticos que ha sufrido por parte de sus propietarios y en diferentes épocas, como de valores que el visitante proyecta en él.

- Necesidad de planes de seguimiento periódicos, que aseguren su mantenimiento a medio y largo plazo, sin contar con drenajes, canalización de aguas, podas, tratamientos fungicidas, prevención de plagas, eliminación de ejemplares no deseados, aireación y abonado, entre otros. 
Figura 4. Jardines de la Finca del Marqués de Valdecilla (Medio Cudeyo, Cantabria).

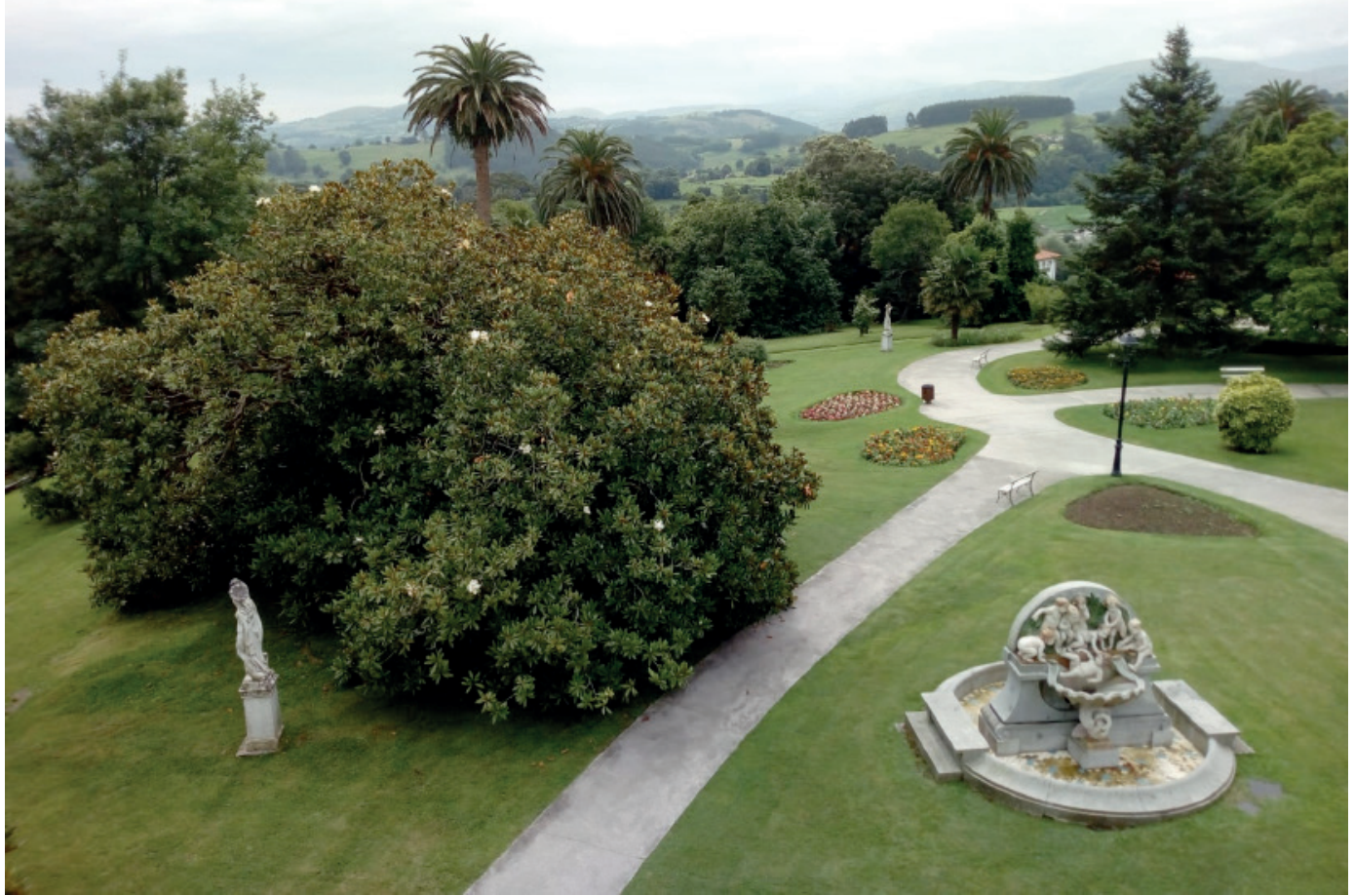

Foto: Guillermo Berman.

La dimensión cultural de este patrimonio y los problemas inherentes a su conservación se abordarían en sucesivos encuentros auspiciados por ICOMOS/IFLA en Fontainebleau (1971), París (1972), Granada (1973), Bruselas (1974), Zeist (Holanda, 1975), Bruselas (1976), Praga (1977), París (1978), Bruselas (1979) o Barcelona (1980) ${ }^{25}$. Pero será en la Carta de Florencia (1981) cuando se mencione expresamente sobre los jardines considerados como históricos y, por tanto patrimonio cultural. En su art. 1 se definen como "una composición arquitectónica y vegetal que, desde el punto de vista de la historia o del arte, tiene un interés público". Como tal, está considerado como un monumento. Esa atribución de monumento otorga al jardín histórico una dimensión cultural que va más allá de ser un mero espacio natural interesante por sus especies botánicas o por su valor ecológico. Esto abrió la posibilidad de que las normativas de los diferentes países lo trataran como tal. En nuestro ordenamiento jurídico, las casas museo reconocidas como museos gozan del máximo nivel de protección, Bien de Interés Cultural (BIC), incluyendo los bienes conservados en ella, atribución que entendemos se hace extensiva a los jardines, porque es otro bien de la casa museo con la única diferencia que es un elemento "exterior" de la vivienda, del edificio en su dimensión arquitectónica. Además, en la LPHE los jardines históricos, que son los propios de estas casas museo, son un tipo específico de BIC inmueble.

Un aspecto controvertido es el de su "autenticidad", porque el valor de la antigüedad no se puede plantear desde la perspectiva de la estricta preservación de un monumento. La Carta de Florencia la define tanto "una cuestión de diseño y proporción de sus partes como de su composición ornamental, o de la elección de los vegetales y materiales inorgánicos que lo constituyen" (art. 9). Es un criterio que se basa en la credibilidad y veracidad de los valores, expresados a través de atributos como el diseño, la forma, los materiales, la función, entre otros, en el que también insiste el Documento de Nara sobre la Autenticidad (1994). La recuperación de un jardín tiene que diferenciarse de una creación ex novo que pueda llevar a la creación de un pastiche o de un falso histórico. No se pueden eliminar especies 
botánicas y plantar otras con la idea de impresionar o dejar una huella personal. Tampoco basta con plantar árboles y esperar a que crezcan. Hay que tener clara una planificación. Como señala Baridon, la búsqueda de un "efecto" no debe limitarse a los aspectos decorativos ${ }^{26}$. Cuando hay que plantar nuevos elementos o sustituir los deteriorados, como sucede con los jardines del Museo Sorolla ${ }^{27}$, se puede evocar, de una manera simbólica, el espíritu del lugar. A pesar de esta "alteración" es posible rememorar la historia de la casa donde Sorolla vivió así como la de sus descendientes. Sigue siendo un lugar donde los acontecimientos que tuvieron una vez lugar están presentes y el público puede conocer los hechos que tuvieron lugar en esos jardines, pero debe reencontrar el contexto históricos que les corresponde. Forma, pues, un palimpsesto, siguiendo a Pasolini Dall'Onda (1975: 33): este nuevo jardín se reescribe, modifica, corrige, reutiliza, sin olvidar las trazas de lo que fue en origen. Un ejemplo se encuentra en el del Museo Cerralbo, cuyo aspecto actual no es el original, sino que responde a una recreación realizada por la paisajista Lucía Serredi en 1995, siguiendo la idea original de un boceto dibujado por el Marqués de Cerralbo hacia $1880^{28}$.

\section{Conclusiones}

La gama de lo que se considera patrimonio se ha extendido en los últimos años, desde su inicial consideración como hito singular sin relación con el entorno. En la práctica supone un cambio conceptual importante que se ha materializado en la existencia de numerosas tipologías (sitios arqueológicos, patrimonio industrial, rutas del patrimonio o jardines, entre otros). En el caso del último queremos llamar la atención sobre la necesidad de considerarlo como una unidad expositiva de la casa museo. Es un espacio doméstico compuesto tanto de elementos naturales como de la naturaleza ordenada por el hombre. Su apertura pública implica una serie de amenazas, pero también debemos ver una serie de oportunidades sociales, económicas o ambientales. Existen experiencias etnográficas en algunas casas museo que son un ejemplo de cómo poder dar respuestas a los nuevos retos del turismo cultural y del uso sostenible de los recursos, como las casas museo del territorio (Pérez Mateo, 2019). La Casa de las Doñas (Enterrías, Cantabria), gestionada por la Asociación Habitat, Terrazgo y Monte, configura un paisaje cultural de gran valor (Pérez Mateo, 2018b). Sus propietarios trabajan con huertos experimentales y cultivan especies autóctonas, propias del Valle de Cereceda, contribuyendo positivamente a su conservación. Lo que se ha plasmado por ejemplo en el Proyecto "El Colmenar de las Doñas", de Francisco Gutiérrez Alonso y Gema García Gutiérrez, una empresa productora de miel y cera que pretende reorientarse hacia la producción ecológica e integrarse en el sello de calidad de la Denominación de Origen Protegida Miel de Liébana. Por su defensa de los valores etnográficos y territoriales del paisaje cultural de Enterrías y Vega de Liébana y por dinamizar su zona rural transmitiendo a la ciudadanía esos valores recibió el reconocimiento del Grupo Alceda 2018 a las Buenas Prácticas Patrimoniales. Otra experiencia etnográfica es la del Caserío Museo Igartubeiti (Ezkio-Itsaso, Guipúzcoa), vivienda y lagar de sidra. Cada otoño se pone en funcionamiento para elaborar la sidra según la técnica empleada hace 500 años y vecinos de la localidad representan a la familia Kortabarria, sus habitantes en el siglo XVII (Urquijo y Bullen, 2009: 58-59). El público conoce la elaboración tradicional de la sidra, desde su recogida en el árbol hasta su embotellamiento. Además, puede disfrutar de un taller de elaboración de jabones naturales y en su huerto ecológico hay plantas medicinales y aromáticas que informan de dónde proceden, pudiendo conocer sus propiedades y aplicaciones. Estos nuevos retos se manifiestan con funciones educativas y didácticas, como espacio escolar, de aprendizaje y de recreo, revalorizando los hitos más relevantes de su pasado, sin renunciar a su carácter, que se potencia con el empleo de etiquetas alusivas a la procedencia de los cultivos (Casa de las Doñas, Caserío Igartubeiti).

Cuando estos jardines se musealizan, no debemos olvidar que hay pocos que se conservan intactos ${ }^{29}$, como los del palacete asturiano de La Quinta ${ }^{30}$ (Cudillero) o los de la Fundación Rodríguez-Acosta (Granada), entre otros. Lo habitual es que se hayan transformado o desaparecido, adaptándose a las actuales condiciones climáticas. Pero estos cambios no deben afectar a los valores del lugar. La supervivencia del género humano pasa por la puesta en valor y respeto a la naturaleza, adoptando un enfoque integral que incluya su dimensión material e inmaterial en todas las escalas de la planificación. $\mathrm{Su}$ apertura pública debe implicar una accesibilidad compatible con su conservación. Sería necesario definir una filosofía de la conservación y promover su atractivo entre el público. La realidad nos muestra que la mayoría no tienen suficiente grado de accesibilidad, por lo que hay una variedad de soluciones que se pueden llevar a cabo (miradores, puntos de observación que permitan la accesibilidad visual de esa zona, pavimentos antideslizantes, rampas o elementos elevadores, bancos y apoyos isquiáticos, 
señalización adaptada, recursos interpretativos variados, etc.) (Espinosa y Bonmatí, 2013: 65 y ss), que deben tener el menor impacto visual. Asimismo, hacemos hincapié en la importancia de una adecuada formación, porque el cuidado de la naturaleza, del agua o del terreno requiere de un corpus teórico de específica aplicación. Como señala la Carta de Florencia "exige mayores cuidados continuos por medio de personas cualificadas. Conviene que una enseñanza apropiada asegure la formación de esas personas, ya se trate de historiadores, arquitectos, paisajistas, jardineros o botánicos" (art. 24).

Nos hemos acostumbrado a ver las especies vegetales exóticas (ficus, magnolios, camelias, araucarias, castaños de indias, etc.) como algo habitual, cuando fueron objeto de coleccionismo en las Wunderkammern europeas y de interés científico durante la Ilustración, cuando la botánica y otras ramas de la ciencia natural tendrían entonces un papel destacado. Estos ejemplares tienen una envergadura diferente a los autóctonos, propios de la cuenca del Mediterráneo (moreras, naranjos, limoneros, cipreses) ${ }^{31}$ y su presencia en las casas museo responde a las preferencias de su propietario. Su culto sigue estando presente en nuestros días. Un ejemplo es la creación, en Galicia, de la Ruta de la Camelia $^{32}$, un itinerario que incluye doce inmuebles y jardines con la camelia como protagonista, una planta procedente de China y Japón. Esta ruta implica que todos los lugares son importantes y contribuyen al resultado final, porque cada uno aporta sus propias características. Algunos de estos inmuebles (paradores, pazos) son casas museo, como la Casa Museo Rosalía de Castro o el Pazo Quiñones de León (Vigo), pero otros son privados, como el Pazo de Oca (A Estrada, Pontevedra), gestionado por la Fundación Casa Ducal de Medinaceli.

En un contexto de creciente interés social por el paisaje, es necesario impulsar el conocimiento de este patrimonio natural e integrarlo en la salvaguardia y puesta en valor del patrimonio cultural. El jardín histórico es el reflejo de una personalidad o una generación que lo hizo posible. Y su atractivo entre el público es indudable. Por ello debemos priorizar las acciones basadas en la participación y el consenso, con el objetivo de desarrollar sinergias encaminadas a su adaptación al siglo XXI, como estrategia de conservación y de disfrute, en la línea de un uso público y un aprovechamiento sostenible de los medios naturales. La necesidad de utilizarlo de modo sostenible hace que sea inevitable decidir qué cambios son aceptables y cuáles no respecto a su conservación. Un adecuado Plan Museológico permitiría a la casa museo la posibilidad de convertirla en un producto turístico y recurrentemente utilizado para la creación de itinerarios culturales. Queda mucho por estudiar y descubrir en estos jardines de casas museo, tanto en el trabajo de archivo como en la exploración in situ.

\section{Bibliografía}

Álvarez, Darío 2007. El jardín en la arquitectura del siglo XX. Naturaleza artificial en la cultura moderna. Barcelona: Reverté.

Añón, Carmen 1989. "Jardines históricos del Patrimonio Nacional símbolos de la jardinería española". Reales Sitios: Revista del Patrimonio Nacional, 1: 125-136. 1991. "The Restauration of the King's Garden at Aranjuez". En The Autentic Garden (pp. 97-103). Leiden: Clusius Foundation. 1992. "Alameda de Osuna. El Capricho: il Labirinto". En Il giardino e il tempo (pp. 125-132). Milán: Guerini et Associati. 1993. "El jardín histórico: Notas para una metodología previa al proyecto de recuperación”. En Jardins et sites historiques (pp. 312-325). Madrid: ICOMOS-UNESCO.

Añón, Carmen, Luengo, Mónica y Luengo, Ana 1995. Jardines artísticos de España. Madrid: Espasa-Calpe. Ariza Muñoz, Carmen 1993. "Construcciones de carácter científico, cultural, artístico y religioso en los jardines de Madrid”, Goya, 234: 339-346. 2001. "Jardines que la Comunidad de Madrid ha perdido", Espacio, tiempo y forma. Serie VII, Historia del Arte, 14: 269-290. 2004. "Invernaderos de los jardines de la Comunidad de Madrid”, Anales del Instituto de Estudios Madrileños, 44: 769-798.

Baridon, Michael 2001. "Restauración y puesta en contexto ¿Cuál es el efecto de la Historia en un jardín?”. En Seminario Internacional: Los jardines históricos: aproximación multidisciplinaria. Buenos Aires, Argentina, 17 al 20 de Octubre de 2001, pp. Disponible en: https://www.icomos.org/fr/ressources/ publications/autres-publications/157-articles-en-francais/ressources/publications/393-seminario-internacional-los-jardines-historicos-aproximacion-multidisciplinaria-buenos-aires-argentina-17-al-20-de-octubre-de-2001 [Consultado el 05-11-2018]

Bondi, Liz, Smith, Mick y Davidson, Joyce 2005. Emotional Geographies. Leicester (UK): Ashgate Publishing Group.

Busquets, Jaume 2010. "La educación en paisaje: una oportunidad para la escuela". Revista IBER, Didáctica de las Ciencias Sociales, Geografía e Historia, 65: pp. 7-16. 
Byne, Arthur. y Stapley, Mildred Spanish Gardens and Patios. Nueva York: The Architectural Record, 1928 (1924).

Cabré Aguiló, Juan

Inventario de las obras de arte [...] del Museo del Excelentísimo Sr. D. Enrique de Aguilera y Gamboa, XVII Marqués de Cerralbo, 15 de febrero de 1924 [Ejemplar Manuscrito]. Madrid, AAMCM

Castells, Manuel 2013. La era de la información. Economía, sociedad y cultura. Vol. II: El poder de la identidad. Madrid: Alianza.

Díaz Gutiérrez, Alfredo 2009. "El museo y su entorno natural. La Fundación César Manrique”. En Los museos en la Educación. La formación de los educadores (pp. 130-143). Madrid: Museo Thyssen-Bornemisza.

Dossier elaborado por el Observatorio del Paisaje Disponible en: http://www.catpaisatge.net/dossiers/ jardins/esp/index.php. [Consultado el 24-09-2018]

Espinosa, Antonio y Bonmatí, Carmina 2013. Manual de accesibilidad e inclusión en museos y lugares del patrimonio cultural y natural. Gijón: Trea.

Jardines Históricos (Carta de Florencia 1981). Disponible en: https://www.icomos.org/images/DOCUMENTS/Charters/gardens_sp.pdf [Consultado el 24-09-2018]

Gestión del Patrimonio Mundial Natural 2014. París, UNESCO/ICCROM/ICOMOS/UICN.

Guía La Quinta de Selgas (2016). Asturias: Fundación Selgas-Fagalde.

Hobhouse, Penelope 1994. Plants in Garden History. Pavilion, Londres.

Luengo Añón, Ana 2008. Aranjuez. Utopía y realidad. La construcción de un paisaje. Madrid: Instituto de Estudios Madrileños, CSIC y Ediciones Doce Calles.

Martínez-Correcher y Gil, Consuelo 2000. "Importancia de los jardines históricos privados", Jardines históricos privados. espacios por descubrir. Madrid: Fundación de Casas Históricas y Singulares: 13-25. 2011. "XXX Aniversario de la restauración del Real Jardín Botánico de Madrid: cómo se gestó", PARJAP. Boletín de la Asociación Española de Parques y Jardines, 64: 36-40.

Morales Saro, $M^{a}$ Cruz 1994. "Mnemosine en el Ocio del Erudito. El Jardín de la Quinta Selgas en Cudillero (Asturias)". En Núñez Rodríguez, Manuel (ed.), El rostro y el discurso de la fiesta (pp. 263278). Santiago de Compostela: Universidad de Santiago de Compostela.

Mulet Gutiérrez, $\mathrm{M}^{\mathrm{a}}$ Josep, Oliver Torelló, Juan Carlos y Sebastián Sebastián, María 2019. "La casa como metáfora del viaje. Fotógrafos y arquitectos en Mallorca". En La casa. Espacios domésticos. Modos de habitar. II Congreso Internacional Cultura y Ciudad, Granada 23-25 enero 2019 (pp.1993-2003). Madrid, Abada Editores.

Muthesius, Hermann 1979. The English House. New York: Rizzoli.

Nogué, Joan 2015. "Emoción, lugar y paisaje". En Puigbert, Laura y Bretcha, Gemma (ed.): Teoría y paisaje II: Paisaje y emoción. El resurgir de las geografías emocionales (pp. 139-147). Olot: Observatorio del Paisaje de Cataluña. Barcelona: Universidad Pompeu Fabra.

NTJ 15 H Gestión de Jardines Históricos. Colección de Normas Tecnológicas de Jardinería y Paisajismo (2018). Barcelona: Fundació de la Jardineria i el Paisatge.

Pasolini Dall'Onda, Desideria 1975. "Restauro del verde storico nella pianificazione del territorio", Italia nostra, 128: 33-40.

Pasti, Umberto 2014. Jardines, los verdaderos y los otros. Madrid: Elba.

Pérez Mateo, Soledad 2018. "Vega Inclán y las casas museo: un concepto inédito del turismo cultural en la España de Alfonso XIII". Cuadernos de turismo, 42: 421 -445. 2019. "El territorio como elemento de identidad de una casa museo". La Torre del Virrey. Revista de Estudios Culturales. 26: 1-28. 2016. Las casas museo en España. Análisis de una tipología museística singular. (Tesis Doctoral Inédita). Murcia: Universidad de Murcia.

Sancho Gaspar, José Luis 1988. “Aranjuez y el arte del jardín durante el reinado de Carlos III”, Reales

Sitios: Revista del Patrimonio Nacional, 98: 49-59. 1995. La arquitectura de los Sitios Reales: catálogo histórico de los palacios, jardines y patronatos reales del Patrimonio Nacional. Madrid: Patrimonio Nacional.

Sancho Gaspar, José Luis y Mencos, Eduardo 2006. Jardines Reales de España. Madrid: Patrimonio Nacional y Aldeasa.

Soria Carreras, Santiago 1995. "La gestión del Patrimonio Nacional en los jardines del Real Sitio de San Lorenzo de El Escorial”. En Añón, C. (coord.). Jardines y paisajes en el arte y en la historia (pp. 229-244). Madrid: Universidad Complutense. 2005. "Aranjuez, más de mil años de jardinería y ordenación del territorio". En González Alarcón, $\mathrm{M}^{\mathrm{a}}$ T. y V. Tovar Marín (coords). Los Reales Sitios, Vol 2 (Palacio Real de Aranjuez) (pp. 51-74). 
Spala, Javier 2014. "Gabinete de Jardines Históricos. Los viveros y las exposiciones de plantas en Madrid durante el siglo XIX”, Boletín de la Fundación de Casas Históricas y Singulares, 2: 34-50.

Tejedor-Cabrera, Antonio 1998. Jardines históricos de Andalucía arquitectura y conservación de sus paisajes privados. (Tesis Doctoral Inédita). Sevilla: Universidad de Sevilla. 1999. "El jardín histórico en Andalucía: reflexiones para una tutela del paisaje patrimonial”, PH Boletín 27: 128-137.

Tito Rojo, José y Casares Porcel, Manuel 1998. "La restauración del Jardín Botánico de la Universidad de Granada", Parjap, 5: 17-21. 1999a. El Carmen de la Victoria. Historia de un jardín regionalista. Granada: Universidad de Granada. 1999b. "Especificidad y dificultades de la restauración en jardinería”, $P H$ Boletín, 27: 138-145.

Tito Rojo, José 1997. Restauración en Arquitectura del Paisaje. Ensayo metodológico aplicado al Carmen de los Mártires y otros jardines granadinos del siglo XIX. (Tesis Doctoral). Granada: Universidad de Granada.

Vaquero, Lurdes et al. 2010. Museo Cerralbo. Guía. Madrid: Ministerio de Cultura.

Varela, Enrique 2019. Los jardines de la casa Sorolla. Biografía de una obra de arte. Madrid: Fundación Museo Sorolla-Editorial Palacios y Museos.

VV. AA. 2011. Conociendo a nuestros visitantes. Museo Sorolla. Madrid: Ministerio de Educación, Cultura y Deporte.

\section{Notas}

1 En la Carta de Atenas sobre la Conservación de Monumentos de Arte e Historia (1931), promovida por la Oficina Internacional de Museos, podemos encontrar una de las primeras referencias legislativas que recogen la transformación de lo natural hacia una perspectiva cultural. Asimismo, no debemos olvidar las experiencias de gestión de entidades como la UNESCO, la UICN (Unión Internacional para la Conservación de la Naturaleza) y otros organismos consultivos del Patrimonio Mundial, ICCROM (Centro Internacional de Estudios para la Conservación y la Restauración de los Bienes Culturales) e ICOMOS (Consejo Internacional de Monumentos y Sitios).

2 Fueron los primeros jardines que se declararon "Monumento", en 1931

3 Destacan, entre otros, el Monte de El Pardo, los Bosques de Riofrío y La Herrería, el Valle de Cuelgamuros, los Jardines de La Granja y Aranjuez, gestionados a través de la Dirección de Inmuebles y Medio Natural, de acuerdo con la modificación de su Reglamento, realizada por el Real Decreto 214/2014, de 28 de marzo. Sin ánimo de exhaustividad cabe mencionar algunas publicaciones sobre jardines de inmuebles de Patrimonio Nacional, que consideramos "casas museo" por ser residencias reales habitadas en distintos momentos históricos, como las aparecidas en la revista Reales Sitios, editada por Patrimonio Nacional desde 1964, o de autores como Darío Álvarez (2007); Carmen Ariza (1993, 2001, 2004); Carmen Añón (1989); Ana Luengo (2008); José Luis Sancho (1988, 1995, 2006); o Santiago Soria (1995, 2005), entre otros.

4 Estos inmuebles privados, que denominamos "casas históricas", son aquéllos que conservan todos sus interiores históricos, permaneciendo prácticamente inalterados hasta nuestros días. Su semejanza con la casa museo se basa en la existencia de unos espacios domésticos habitados, pero no son espacios musealizados y muchos mantienen su función residencial, lo que ha propiciado su conservación. La casa histórica se diferencia de la casa museo en que es de propiedad privada y, por lo tanto, de acceso restringido. Aunque su apertura pública se realice de forma puntual no se considera casa museo porque no cumple las funciones propias de un museo (arts. 1 y 2 del Real Decreto 620/1987, de 10 de abril, del Reglamento de Museos de Titularidad Estatal y del Sistema Español de Museos). Hay ocasiones en las que se abren sólo las estancias visitables, mientras que las dedicadas a vivienda no son visitadas por el público. Estas ideas se desarrollan en la Tesis Doctoral de la autora, "Las casas museo en España. Análisis de una Tipología Museística Singular" (Universidad de Murcia, 2016), de próxima publicación.

5 Fundada en Barcelona en 1973, la forman profesionales de la jardinería pública y privada.

6 Creada en 1998, con sede en Madrid, gestiona la Asociación de Propietarios de Casas Históricas y Singulares.

7 En la década de los años 20 del siglo XX Arthur Byne y Mildred Stapley, bajo su faceta de apasionados hispanistas, rastrearon el territorio español en busca de sus riquezas artísticas, que plasmaron en una serie de publicaciones convertidas en anales de nuestra historiografía.

8 Categoría establecida en la reunión sobre Paisajes Culturales celebrado en La Petit Pierre (Francia) en 1992.

9 La museografía de la casa museo no se limita únicamente a sus diferentes unidades de habitación, sino que su domesticidad se prolonga al exterior, configurando un patrimonio natural de enorme valor. Véase Pérez Mateo, 2018.

10 El desarrollo de las categorías se detalla en la Tesis Doctoral de la autora, quien propone reducirlas a tres partiendo del análisis de tres variables (personalidad, territorio, período histórico y/o estilo cultural), dando lugar a la casa museo de personalidad, la casa museo del territorio y la casa museo de período histórico y/o contexto cultural.

11 Proyectados por Fortunato Selgas a partir de 1864 sintetizan las nuevas tendencias de la jardinería europea, en concreto el eclecticismo de los jardineros franceses Grandpont y Jean Pierre Rigoreau.

12 El jardín paisajista, también denominado jardín inglés, comenzó en Inglaterra hacia 1720 e influirá notablemente en España, influyendo en los cambios que experimentarán los jardines de los palacios de la nobleza, como la casa-jardín de los Osuna, en Madrid. El período isabelino sería el momento de mayor difusión del jardín a la inglesa.

13 El coleccionismo de plantas se convierte en una pasión para muchos aristócratas, moda que tiene un enorme arraigo en Inglaterra, con la construcción en las casas burguesas de un invernadero adosado en el Kitchen Garden. 
14 El derribo de la mayoría de los palacetes del Paseo de la Castellana en la década de 1960 nos ha privado de documentación sobre sus jardines e invernaderos y sobre los profesionales que intervinieron en ellos. Pero en la prensa de finales del siglo XIX podemos encontrar descripciones sobre las exposiciones que se celebraban de plantas pudiendo conocer algunos datos sobre las especies, los jardineros, aficionados o profesionales, o los lugares donde se desarrollaron los cultivos.

15 Véase Vaquero, L. et al, pp. 92-93.

16 Cabré Aguiló, J. Inventario de las obras de arte [...] del Museo del Excelentísimo Sr. D. Enrique de Aguilera y Gamboa, XVII Marqués de Cerralbo, 15 de febrero de 1924 [Ejemplar Manuscrito]. Madrid, AAMCM.

17 Por infraestructura hidráulica entendemos la que es necesaria para el funcionamiento de fuentes y estanques, canales y acequias para el riego, que ha generado un patrimonio inmueble que podemos apreciar en algunas de las casas museo objeto de este estudio.

18 La historia de la construcción de los jardines de esta casa museo, que es la de Sorolla como arquitecto de jardines, ha sido objeto de reciente publicación. Véase Varela, 2019.

19 Los modelos de arquitectura doméstica inglesa y su vinculación con el paisaje tuvieron gran difusión a raíz de la publicación, en 1904, del libro Das englische Haus, del arquitecto alemán Hermann Muthesius (su versión inglesa The English House. New Yok, Rizzoli, data de 1979 y es la que utilizamos).

20 La UICN define un área protegida como "un espacio geográfico claramente definido, reconocido, dedicado y gestionado, mediante medios legales u otros tipos de medios eficaces para conseguir la conservación a largo plazo de la naturaleza y de sus servicios ecosistémicos y sus valores culturales asociados”. Véase Gestión del Patrimonio Mundial Natural, 2014: 16 .

21 Es indudable que estos jardines incrementan la experiencia del confort, como el ejemplo del Museo Sorolla, una de las casas museo del Ministerio de Cultura y Deporte mejor valoradas en cuanto a lo positivo de la experiencia del visitante, cuyos jardines con abundantes bancos y asientos permiten el descanso y la relajación. Véase VV. AA. (2011): Conociendo a nuestros visitantes. Museo Sorolla, Madrid, Ministerio de Educación, Cultura y Deporte.

22 El Consejo Internacional de Museos (ICOM) creó en 2017 un comité sobre la definición de museo, perspectivas y posibilidades (MDPP), para analizar las tendencias sociales y asesorar al ICOM sobre una posible revisión del concepto de museo.

23 Mantenimiento sería podar, recortar, eliminar hierbas no deseadas, regar, abonar; conservar sería reponer y recolocar los elementos vegetales y recuperar equivaldría a rehacer los elementos naturales a partir de la documentación y de los restos conservados. Por su fragilidad debe ser objeto de evaluaciones y actuaciones permanentes de conservación preventiva, así como formar parte de las políticas de planes de protección medioambiental. Véase NTJ 15H Gestión de Jardines Históricos, 2018 .

24 No pretendemos recoger una bibliografía de restauración de jardines de casas museo españolas, sino subrayar algunos ejemplos.

25 El valor del jardín histórico como parte del patrimonio cultural ya fue reconocido en 1970 por ICOMOS (Consejo Internacional de Monumentos y Sitios). Constituye un Comité Mixto con la IFLA (Federación Internacional de Arquitectos Paisajistas). Este Comité ICOMOS-IFLA se formó en 1970 y es el Comité Internacional de Jardines Históricos y Paisajes Culturales. Los textos legislativos sobre esta materia son fundamentalmente internacionales y han sido ampliamente estudiados, por lo que no nos detendremos en ellos.

26 Véase Baridon, 2001.

27 Existe abundante documentación fotográfica de los jardines originales del Museo Sorolla, cuyas plantas necesitaban mucha luz. Las condiciones lumínicas actuales del jardín (está rodeado de otros edificios de gran altura) no permitían poner las mismas u otras similares, de manera que se procedió a la sustitución de los elementos naturales originales por otros más acordes con las actuales condiciones ambientales. Véase Varela, 2019.

28 La Memoria del Proyecto de Intervención en el Jardín del Museo Cerralbo, realizada por Lucía Serredi en 1995, se conserva en el Archivo Administrativo del Museo Cerralbo.

29 Por ejemplo, los jardines de la Fundaci n Apel • les Fenosa (El Vendrell, Tarragona), con especies aut ctonas (palmeras, olivos, limoneros), fueron creados para el disfrute personal de sus propietarios y en la actualidad se ha convertido en un espacio expositivo que muestra las obras del escultor.

30 En el año 2006 los jardines fueron reconocidos con el premio al mejor jardín español, otorgado por la Sociedad de Amigos del Real Jardín Botánico de Madrid. Para más información véase el artículo de Morales Saro citado y la Guía La Quinta de Selgas (2016).

31 Sobre las especies vegetales que se cultivan a lo largo de los siglos en los jardines véase Hobhouse, 1994.

32 Disponible en http://www.turismo.gal/que-facer/ruta-da-camelia?langId=es_ES [Consultada el 26-09-2018]. Asimismo, se pueden consultar referencias a las camelias de estos inmuebles en la revista Camelia, editada en el año 2003 por la Sociedad Española de la Camelia y de publicación semestral. 